\title{
Function and Distribution of a Lantipeptide in Strawberry Fusarium Wilt Disease-Suppressive Soils
}

\author{
Da-Ran Kim, ${ }^{1}$ Chang-Wook Jeon, ${ }^{2}$ Jae-Ho Shin, ${ }^{3}$ David M. Weller, ${ }^{4}$ Linda Thomashow,,${ }^{4}$ and \\ Youn-Sig Kwak ${ }^{1,2,+}$ \\ ${ }^{1}$ Department of Plant Medicine and Institute of Agriculture \& Life Sciences, Gyeongsang National University, Jinju 52828 Korea; \\ ${ }^{2}$ Dvision of Applied Life Science (BK21Plus), Gyeongsang National University; ${ }^{3}$ School of Applied Biosciences, Kyungpook \\ National University, Daegu Korea; and ${ }^{4}$ United States Department of Agriculture-Agriculture Research Service, Wheat Health, \\ Genetics and Quality Research Unit, Pullman, WA 99164, U.S.A.
}

Accepted 3 September 2018.

\begin{abstract}
Streptomyces griseus $\mathrm{S} 4-7$ is representative of strains responsible for the specific soil suppressiveness of Fusarium wilt of strawberry caused by Fusarium oxysporum f. sp. fragariae. Members of the genus Streptomyces secrete diverse secondary metabolites including lantipeptides, heat-stable lanthionine-containing compounds that can exhibit antibiotic activity. In this study, a class II lantipeptide provisionally named grisin, of previously unknown biological function, was shown to inhibit $F$. oxysporum. The inhibitory activity of grisin distinguishes it from other class II lantipeptides from Streptomyces spp. Results of quantitative reverse transcription-polymerase chain reaction with lanMspecific primers showed that the density of grisin-producing Streptomyces spp. in the rhizosphere of strawberry was positively correlated with the number of years of monoculture and a minimum of seven years was required for development of specific soil suppressiveness to Fusarium wilt disease. We suggest that lanM can be used as a diagnostic marker of whether a soil is conducive or suppressive to the disease.
\end{abstract}

Fusarium oxysporum is a complex species comprising ubiquitous soil-borne plant pathogens with more than 150 hostspecific forms or forma speciales (Baayen et al. 2000). These pathogens invade the root epidermis and extend into the vascular tissue, in which they colonize the xylem vessels and produce mycelium and conidia (Beckman 1987). The characteristic wilt symptoms result from severe water stress, mainly due to vessel clogging (Beckman 1987), and are characterized by yellowish leaves, irregular leaf formation, and wilted plants. There may be 30 to $40 \%$ yield loss, which can increase to $80 \%$ under favorable weather conditions (Kapoor 1988).

As a consequence of the intensive use of fungicides, fungicide-resistant subpopulations of Fusarium spp. and other pathogens have emerged and are a serious problem in crop production (De Cal et al. 2005; Liu et al. 2007). Preplant soil

Da-Ran Kim and Chang-Wook Jeon contributed equally to this work.

${ }^{\dagger}$ Corresponding author: Y.-S. Kwak; E-mail: kwak@gnu.ac.kr

Funding: This research was supported by the Rural Development Administration Next-Generation BioGreen 21 Program (PJ013250).

*The $\boldsymbol{e}$-Xtra logo stands for "electronic extra" and indicates that two supplementary figures and five supplementary tables are published online.

@ 2019 The American Phytopathological Society fumigation with methyl bromide (MB) or mixtures of $\mathrm{MB}$ and chloropicrin has been standard practice for controlling soilborne pathogens (De Cal et al. 2005), but soil fumigation is not completely efficient and is discouraged as environmentally unsound. In contrast, biological control mediated by Fusarium disease-suppressive soils has been recognized for decades (Alabouvette et al. 1993; Mazurier et al. 2009; Scher and Baker 1980, 1982; Sneh et al. 1984; Weller et al. 2002). More recently, biological control based on phytobiome information has become an exciting and rapidly developing research area with important implications for plant productivity. In one such example, Cha et al. (2016) reported control of the strawberry wilt pathogen F. oxysporum f. sp. fragariae by a Streptomyces isolate selected from the microbiome of strawberry grown in a 15year continuous monoculture field that had become suppressive of wilt disease. In that report, S. griseus S4-7 was both necessary and sufficient to protect against the strawberry wilt pathogen.

Members of the genus Streptomyces are widely regarded as plant probiotics that protect against a wide range of plant pathogens (Bakker et al. 2010; Zivković et al. 2010). They are characterized as having a complex filamentous-type structure and sporulation and produce lytic enzymes, including chitinases, proteases, and cellulases, as well as numerous antibiotics and secondary metabolites. To date, nearly $75 \%$ of known antimicrobial compounds are derived from this genus. These include important pharmacophores and medical antibiotic derivatives such as vancomycin, erythromycin, tobramycin, capreomycin, daptomycin, chloroeremomycin (precursor for oritavancin), and echinocadin B (Baltz 2008). These compounds are produced by nonribosomal peptide synthetase (NRPS) or polyketide synthase clusters, and antibacterial compounds consistently have originated via these pathways. Also recently reported are lantipeptides, ribosomally synthesized and posttranslationally modified microbial secondary metabolites, many of which have antimicrobial activities (Dufour et al. 2007; Hofmann et al. 2012; Lubelski et al. 2008). For example, lantipeptides are known for their antimicrobial or bacteriocin-like activity (Foulston and Bibb 2010) and they kill by either binding to the cell-wall precursor lipid II, by forming pores in cell membranes, or both, leading to the efflux of small molecules and dissipation of the membrane potential (Breukink et al. 1999). When lantipeptides (structural terminology) are confirmed to have antibiotic function, they are termed lantibiotics. Lantipeptide biosynthesis operons are widely distributed among the actinobacteria, suggesting that they play an important ecological role (Yu et al. 2013; Zhang et al 2015), but 
the biological functions of few of the lantipeptides produced by Streptomyces spp. are known.

Lantipeptides can be subdivided based on their structure and mode of posttranslational modification (Zhang et al. 2012). Class I lantipeptides exhibit a linear secondary structure, are positively charged upon synthesis, and are modified by two distinct LanB and LanC synthetase enzymes. LanB is required for the selective dehydration of Ser or Thr residues in the LanA core peptide to Dha or Dhb. Class II lantipeptides, conversely, exhibit a globular structure, are noncharged (Garg et al. 2013), and the core peptide is modified by a single bifunctional LanM enzyme of 900 to 1,200 amino acids, with an N-terminal dehydratase domain bearing no homology to LanB and a C terminal cyclase domain with only about $25 \%$ sequence identity to LanC, including a conserved zinc-binding motif critical for activity (Li and van der Donk 2007). LanM enzymes share little sequence similarity with one another. Two additional lantipeptide classes also are known. Class III lantipeptides are heat-sensitive molecules with a molecular weight greater than $30 \mathrm{kDa}$ (Breukink et al. 1999) and class IV lantipeptides, discovered in 2010 by genome analysis of a cryptic gene cluster in S. venezuelae, are cyclic structures synthesized via a novel threedomain LanL synthetase (Knerr and van der Donk 2012).

In this study, we identified six lantipeptide biosynthesis gene clusters in the genome of strain S4-7. The class II lantipeptide lan $M$ was found to affect antifungal activity and was developed as a molecular-geographical marker for the distribution of S4-7 in strawberry fields. The results of these surveys revealed that the number of years of strawberry monoculture was strongly correlated with the density of grisin producers in the rhizosphere. Here, we report the successful characterization of the geoecology and biological functions of this novel lantipeptide in the Fusarium wilt disease-suppressive soil system.

\section{RESULTS}

Resequencing the $S$. griseus $\mathrm{S4-7}$ genome and putative antifungal metabolites.

The complete genome sequence of $S$. griseus $\mathrm{S} 4-7$, isolated from the strawberry rhizosphere as a Fusarium wilt-suppressive agent (Cha et al. 2016), was determined via the PacBio RS II single-molecule real-time (SMRT) sequencing platform. De novo assembly of the SMRT reads was undertaken and a genome circular map was generated by analysis with BLAST Ring Image Generator (BRIG) v 0.95. We executed SMRT analysis to produce subreads by trimming and filtering the raw reads utilizing the following parameters: minimum read length $=16,571$, read score $=0.84$, and minimum length $=11,818$. Genome coverage was $83.48 \times$.

The genome consisted of a single linear chromosome of $7,697,387$ base pairs with no plasmids (Fig. 1). Genes were annotated by using the RAST pipeline, and the strain had 6,935 protein coding genes, six ribosomal RNA operons, and $\mathrm{G}+\mathrm{C}$ content of $71.5 \%$. Thirty secondary metabolite gene clusters were predicted by using antiSMASH. These clusters predicted coding for known or unknown secondary metabolites, including four lantipeptides, two bacteriocins, two siderophores, two butyrolactones, three NRPSs, six clusters encoding terpene, two ectoines, three polyketide synthetases, four NRPSs linked to polyketide synthetases, one melanine cluster, and a lassopeptide cluster (Supplementary Table S1).

\section{Lantipeptide biosynthesis genes in S. griseus S4-7.}

AntiSMASH, RAST, and National Center for Biotechnology Information (NCBI) databases were employed to predict the lantipeptide biosynthesis genes in the S4-7 genome (Table 1).
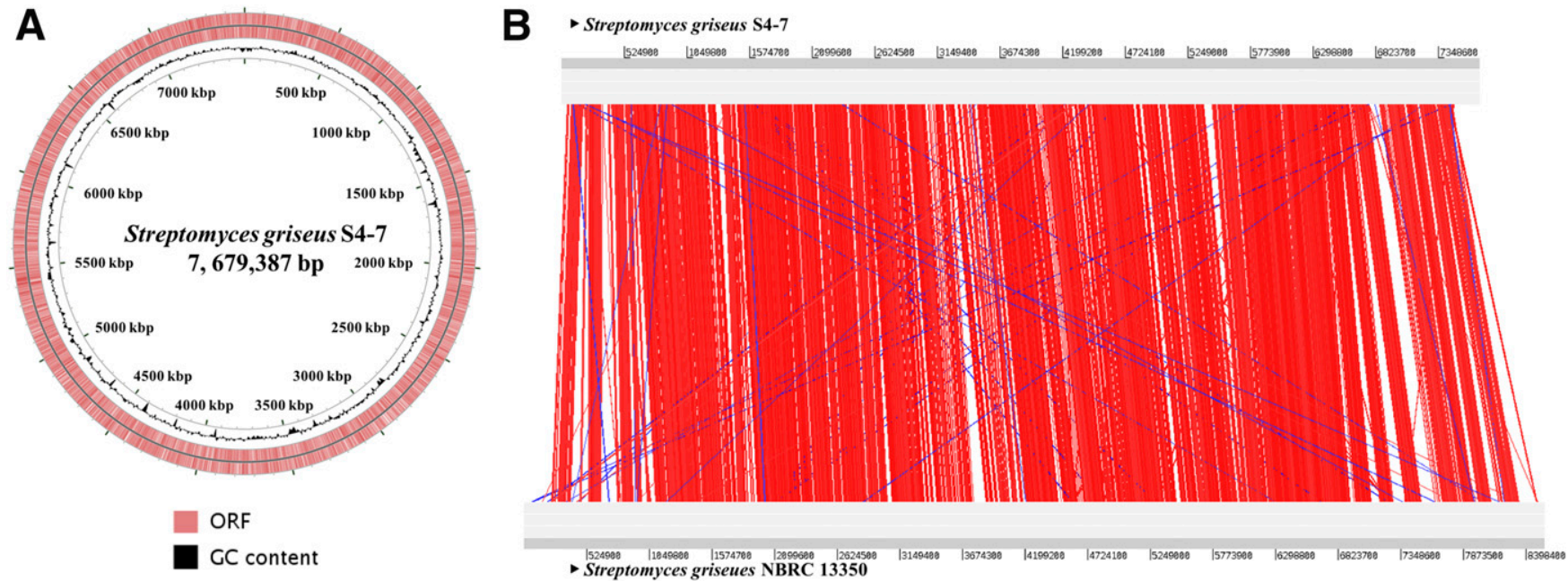

Fig. 1. Streptomyces griseus S4-7 genome circular map and genome comparison with S. griseus NBRC 13350. A, The innermost rings show GC content (black) and open reading frame fragments outside this ring are the alternating bars. The draft genome was analyzed by using BRIG (BLAST Ring Image Generator) v 0.95 . B, For the comparison genome sequence, the shaded blocks indicate regions of DNA similarity.

Table 1. Lantipeptide biosynthesis gene clusters in Streptomyces griseus $\mathrm{S} 4-7^{\mathrm{a}}$

\begin{tabular}{lll}
\hline AntiSMASH & \multicolumn{1}{c}{ RAST } & NCBI \\
\hline Cluster 12-Lan A & Lan A & Lanthionine precursor peptide LanA \\
Cluster 12-Lan L-2 & Lan L-2 & Lanthionine biosynthesis protein LanL \\
Cluster 12-Lan L-1 & Hypothetical protein & Hypothetical protein \\
Cluster 17-Lan B & Lan B & Lanthionine biosynthesis protein LanB \\
Cluster 20-Lan M & Lan M & Lanthionine biosynthesis protein LanM \\
Not detected & Lan C & Lanthionine biosynthesis protein LanC \\
\hline
\end{tabular}

\footnotetext{
${ }^{\mathrm{a}} \mathrm{RAST}=$ rapid annotation using subsystem technology, NCBI = National Center for Biotechnology Information.
} 
With antiSMASH, the genome included three lantipeptide clusters and one thiopeptide-lantipeptide cluster. Two lantipeptide clusters and the thiopeptide-lantipeptide cluster contained lantipeptide biosynthesis genes; cluster 12 included $\operatorname{lan} A$, lanL-1, and lanL-2; cluster 17, the thiopeptide-lantipeptide, included lanB; and cluster 20 contained lanM. lanC was observed in one RAST cluster (Fig. 2). RAST annotation results including lanA, lanB, lan $C$, lanM, and lanL-2 were similar to those of antiSMASH, while the $\operatorname{lan} L-1$ gene differed from the results of antiSMASH analysis. Finally, the prokaryotic genome automatic annotation pipeline in the NCBI database detected lanA, lanL-2, lanB, lanM, and $\operatorname{lan} C$ (Table 1). Taken together, there were minor differences among the results of the three different annotation pipelines. We concluded from the collective results that S. griseus S4-7 includes a total of six lantipeptide biosynthesis genes, which we grouped according to lantipeptide class, with two class I (lanB, $\operatorname{lan} C)$, one class II (lanM), three class III groups (lanA, lanL-1, lan $L-2$ ), and no class IV group genes. Genes $\operatorname{lan} A$, $\operatorname{lan} B$, and lan $C$ already have been described as having involvement in aerial hyphae formation or antibacterial activity, respectively (McAuliffe et al. 2001; Ueda et al. 2002). However, no biological function of lanM has been reported previously in Streptomyces spp.

\section{Biological function of grisin, the LanM lantipeptide.}

Based on the genome information, we then created six lantipeptide biosynthesis gene deletion mutants (lanA, $\operatorname{lan} B, \operatorname{lan} C$, lanL-1, lanL-2, and lanM). The mutants showed differential antagonistic activity against $F$. oxysporum $\mathrm{f}$. sp. fragariae. Four mutants (lanC, lanL-1, lanL-2, and $\operatorname{lan} B$ ) retained their antifungal activity against the pathogen, but two mutants in $\operatorname{lan} A$ and lanM exhibited dramatically reduced antifungal activity on PDK (10 $\mathrm{g}$ of potato dextrose broth, $10 \mathrm{~g}$ of peptone, $20 \mathrm{~g}$ of agar, 1 liter of distilled water) agar after 5 days (Fig. 3). Sporulation of the lanM mutant was similar to that of the wild type and spore color varied from white (at the initiation stage) to gray (at the maturation stage) on PDK media (Fig. 3). LanM

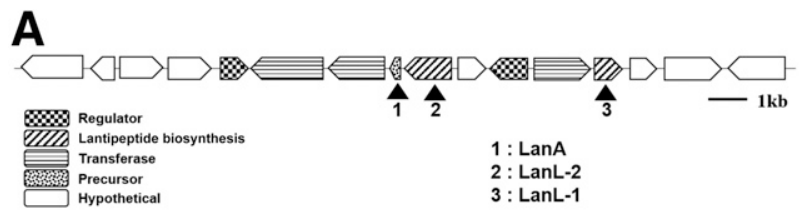

B

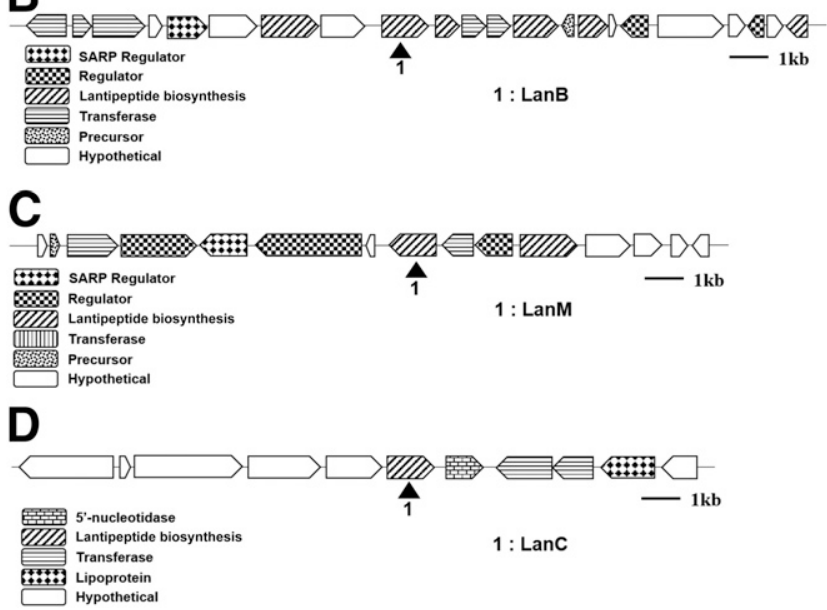

Fig. 2. Gene organization and function of the lantipeptide clusters in S4-7. A, Cluster 12; B, cluster 17; C, cluster 20; and D, LanC protein in RAST cluster. Black arrows indicate locations of homologs knocked out by the pKC1132 suicide vector. was not expressed in the $\Delta l a n M$ mutant (Supplementary Fig. $\mathrm{S} 1$ ), and the function of $\operatorname{lan} A$ already has been related to antimicrobial activity and sporulation (Ueda et al. 2002).

\section{Correlation between density of grisin produced and years of strawberry monoculture.}

The Streptomyces species-specific amplicon primers Fofra $\mathrm{qF}$ and Fofra $\mathrm{qR}$, which target a 512-bp intergenomic region between the transposable elements Han and Skippy (Supplementary Table S2) and lanM gene-specific primer sets targeting a 1,033-bp amplicon were used to screen DNA from 25 different Streptomyces isolates, three from strawberry, one from turfgrass, 11 from kiwifruit, and 10 from various soil sources (Supplementary Table S3). All isolates gave a positive reaction with the Streptomyces-specific primers, but the lanM gene was only detected in the strains from strawberry. Not surprisingly, comparison of the LanM protein sequence from S. griseus S4-7 with LanM sequences from various other bacteria showed that the S4-7 protein differed significantly from previously reported LanM sequences (Supplementary Fig. S2).

DNA samples were extracted from the rhizosphere soil of strawberry plants from 30 different commercial fields located in Sugok-myeon, Sancheong-gun, and Hadong-gun counties in the Republic of Korea and were subjected to quantitative realtime polymerase chain reaction (qRT-PCR) with the lanM and F. oxysporum f. sp. fragariae-specific primers. The results showed that the intergenomic fragment of the pathogen was detected at more than $10^{5}$ copies per gram of soil regardless of the geographical origin of the soils (Fig. 4A). Interestingly however, the presence and density of the lanM gene varied among the samples (Fig. 4B), and only fields with seven or more years of strawberry monoculture attained levels more than $10^{5}$ gene copies of lanM per gram of rhizosphere soil (Fig. 4C). Additionally, Fusarium wilt disease incidence and severity presented a negative correlation with the number of years of monoculture (Fig. 4D; Supplementary Table S4).

\section{DISCUSSION}

Lantipeptides comprise a growing family of over 90 structurally diverse ribosomally synthesized and posttranslationally modified natural products. Historically, these compounds were discovered via antimicrobial screens, but recent advances in genomics and bioinformatics have revealed hundreds of taxonomically distant bacterial strains with putative lantipeptide biosynthetic enzymes that may ultimately yield novel

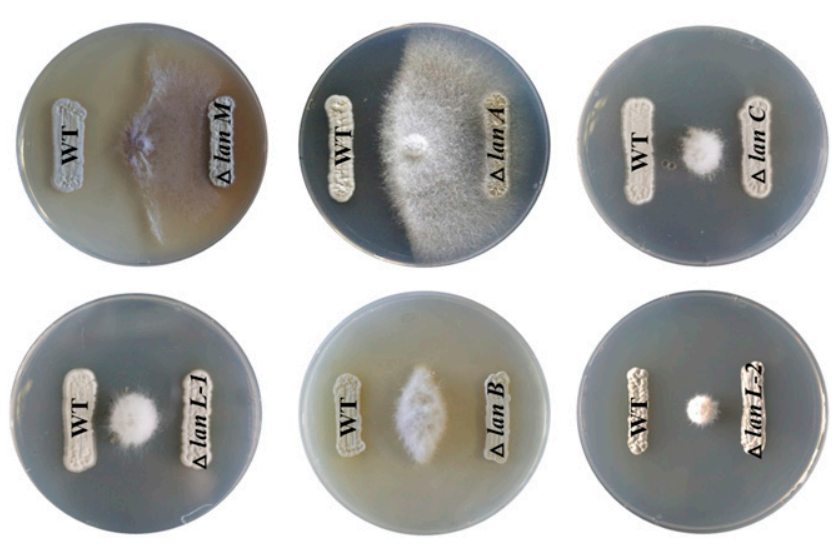

Fig. 3. Antagonism of Fusarium oxysporum f. sp. fragariae by wild-type Streptomyces griseus S4-7 and lantipeptide deletion mutants on PDK agar (10 $\mathrm{g}$ of potato dextrose broth, $10 \mathrm{~g}$ of peptone, $20 \mathrm{~g}$ of agar, 1 liter of distilled water) incubated for 5 days at $28^{\circ} \mathrm{C}$. 
structures and biological activities of potential pharmacological value. These peptides represent a new type of antibiotic produced by Streptomyces spp. In this study, we characterized LanM, a novel lantipeptide synthetase from the Fusarium wilt-suppressive bacterium $S$. griseus S4-7. Genomic sequence analysis revealed that strain S4-7 contains six lantipeptide biosynthesis genes. Of these, genes $\operatorname{lan} A$ and $\operatorname{lan} L$, located in cluster 12 , are perfectly matched with $a m f S$ and $a m f B$, which have been identified as regulators for aerial mycelium formation in S. griseus (Ueda et al. 2002). Genus Streptomyces is characterized as having a complex filamentous-type structure and sporulation, both of which relate to the production of antibiotics. Therefore, the $\operatorname{lan} A$ and $\operatorname{lan} L$ genes were excluded from the major antifungal functions in this study.

Custer 17 includes a different lantipeptide class synthesis gene, lanB. This gene is identical to tpaL from Nocardiopsis sp. strain TFS65-07 (Engelhardt et al. 2010). Antibiotic production by this strain involves the genes tpaC, tpaD, tpaE, tpaF, tpaL, tpaH, and tpaK (Engelhardt et al. 2010). Cluster 20 of strain S47 has a unique single class II lantipeptide biosynthesis gene, lanM, encoding for a lantipeptide with strong antifungal activity that we have provisionally named grisin. Like other class II synthetases, the predicted enzyme includes an $\mathrm{N}$-terminal dehydratase domain and a C-terminal cyclase domain with a

\section{A}

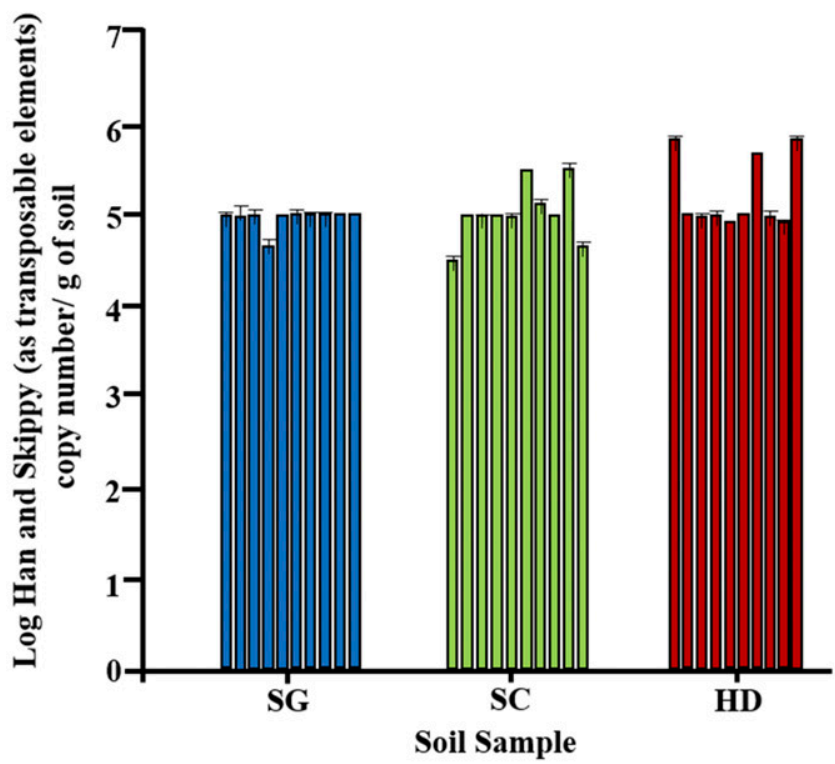

C

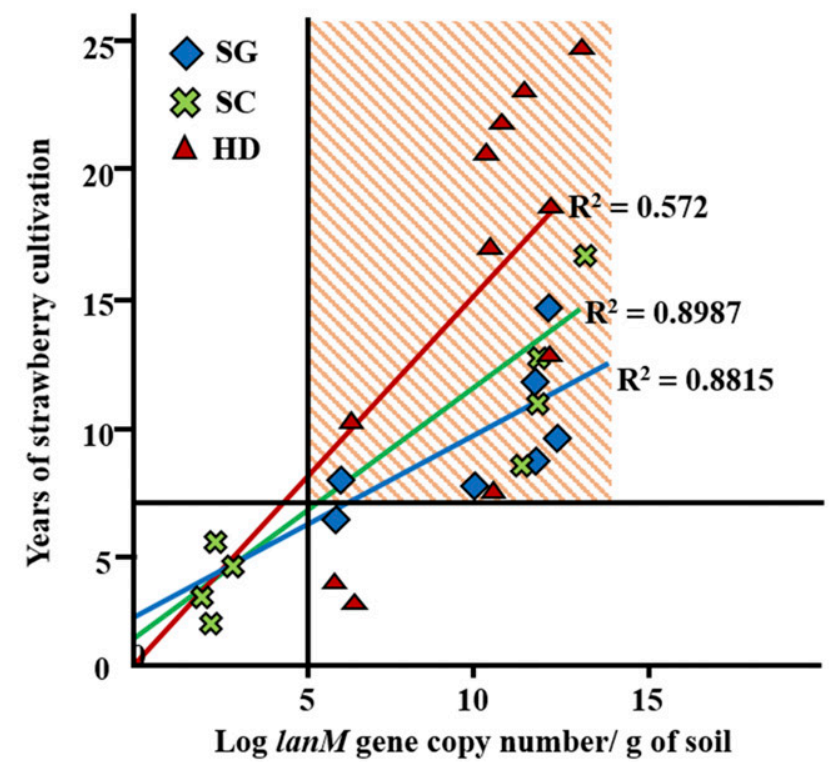

B

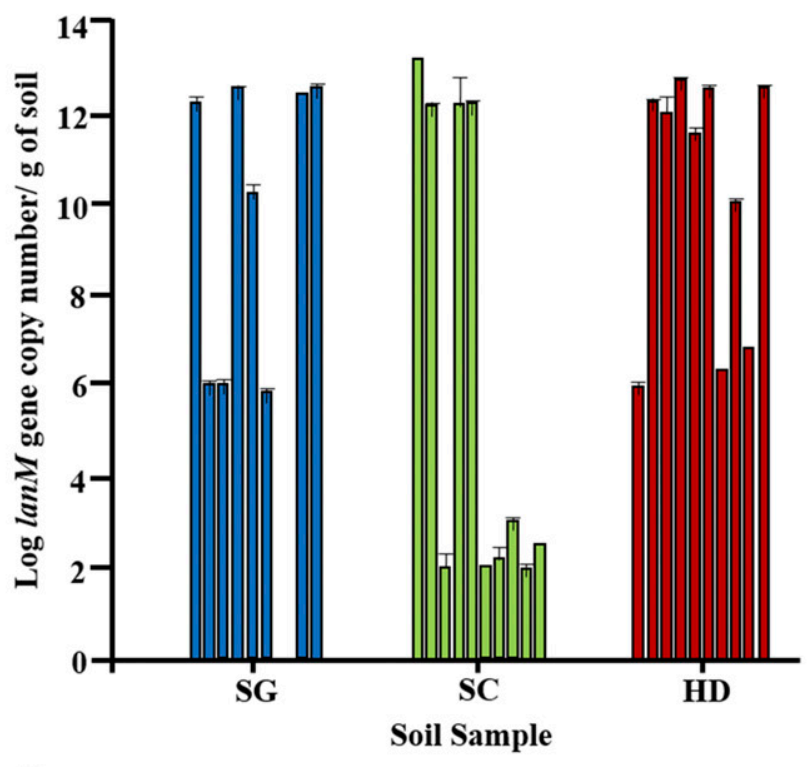

D

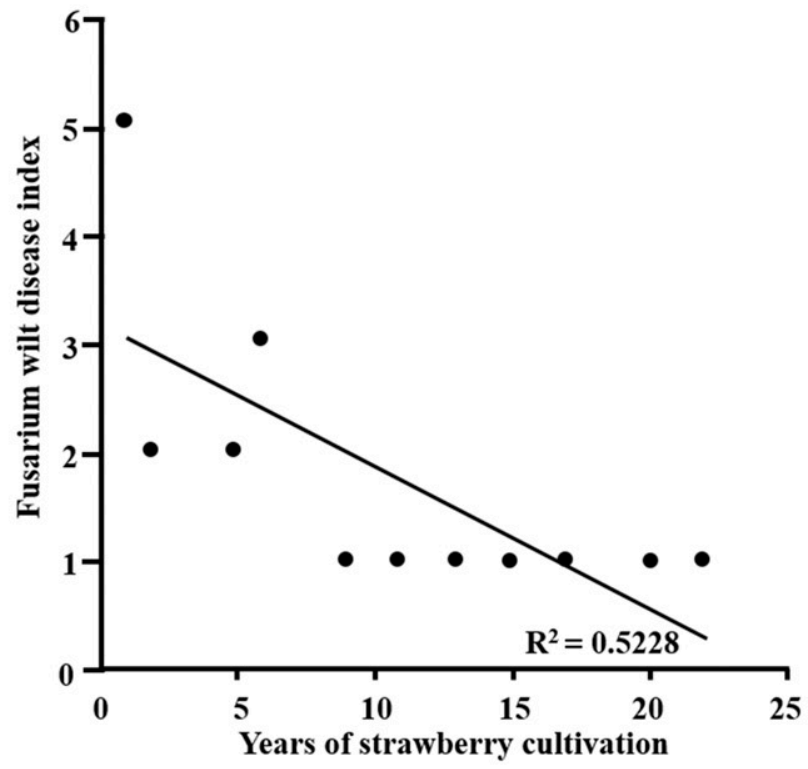

Fig. 4. Quantitative real-time polymerase chain reaction analysis of the absolute copy number of Fusarium oxysporum f. sp. fragariae and lanM-producing genes in soil, illustrating the relationship between lanM gene concentration and years of strawberry monoculture. Relationship between years of strawberry monoculture and Fusarium wilt disease index. Locations of soil sampling include Sugok-myeon (SG), Sancheong-gun (SC), and Hadong-gun (HD). A, F. oxysporum f. sp. fragariae population density in soil samples. B, lanM gene detection in strawberry field soil samples. C, Correlation between lanM-producing Streptomyces population and years of strawberry monoculture. D, Correlation between years of strawberry monoculture and Fusarium wilt disease index. 
zinc-binding site (Goto et al. 2010). However, as it exists in the genus Streptomyces, this type of lantipeptide has not yet been studied. Individual mutants (lanA and lanM) lost antifungal activity against $F$. oxysporum f. sp. fragariae. The S4-7 LanM protein sequence showed no match with previously reported lantipeptide sequences in Streptomyces spp. and, to our knowledge, this is the first study to reveal evidence of LanM biological function. Cha et al. (2016) reported previously that conprimycin has a critical role in the antifungal activity of strain S4-7, and the strain also produces caryolan-1-ol, a volatile compound with significant inhibitory activity (Cho et al. 2017). Grisin is the third compound active against $F$. oxysporum f. sp. fragariae, suggesting that the pathogen may be unable to overcome the arsenal of metabolites produced by this natural probiotic agent in the rhizosphere. The kinetics of synthesis of these compounds is currently under investigation.

Regardless of the cropping system, agricultural soils harbor countless microbes, and long-term monoculture can lead to coevolution between a plant and members of its microbiome, leading to the selection of strains that function as probiotics to overcome certain pathogens. Soils that have undergone this phenomenon are said to exhibit specific suppressiveness and are characterized by their ability to limit disease caused by particular pathogens. In such soils, the disease does not occur because the target pathogen is suppressed by the biocontrol agent (Weller et al. 2002). In take-all decline, the classic example of specific soil suppressiveness, the suppressive agent Pseudomonas brassicacearum produces the antibiotic 2,4diacetylphloroglucinol (DAPG) and must reach a threshold population on roots of at least $10^{5} \mathrm{CFU}$ per gram of rhizosphere soil to provide protection against the take-all pathogen (Raaijmakers and Weller 1998). In general, the transition to suppressiveness in that system requires four to six years of wheat monoculture (Kwak and Weller 2013), and the DAPG biosynthesis locus can be detected by PCR in soils in decline (Mavrodi et al. 2007). Similarly, we detected the lanM gene in $S$. griseus isolates from soils cropped to strawberry but not in isolates recovered from other host plants or from nonagricultural soils. These results suggested that lanM can be used to detect specific grisin-producing Streptomyces strains in the rhizosphere. Accordingly, we developed a unique PCRbased method to evaluate the relationship between the cell density of strains harboring lanM and the number of years of monoculture, and we found that the two were positively correlated. Bacterial densities of up to $10^{5} \mathrm{CFU}$ per gram of rhizosphere soil were detected in strawberry fields after seven or more years of monoculture, even though the Fusarium wilt pathogen population was present at a similar level in all soils regardless of the number of years of monoculture history. These results are consistent with the classic model of specific soil suppressiveness. Moreover, using the approach described here, we have shown that lanM gene detection combined with knowledge of the number of years of strawberry monoculture can provide a potential basis for deciding whether or not the soil will be suppressive of strawberry wilt disease.

To conclude, we have discovered a lantipeptide synthase encoded by a lanM gene in $S$. griseus $\mathrm{S} 4-7$ that contributes to the ability of the bacteria to suppress strawberry wilt disease caused by $F$. oxysporum f. sp. fragariae. The product of LanM has antifungal activity and is the first class II lantipeptide from genus Streptomyces reported to have a biological function. This novel peptide provides antifungal activity to strains with the capacity to produce it, and a marker for the specific suppressiveness of soil in long-term strawberry cultivation systems. We propose that $S$. griseus S4-7 can act effectively against Fusarium wilt because the bacterium produces the major lantibiotictype antibiotic LanM, and we suggest that detection of lanM is predictive of whether or not a soil will have the ability to limit Fusarium wilt disease in many cropping systems. To become suppressive against Fusarium wilt disease in strawberries does, however, require a minimum 7-year monoculture strategy. This finding is critical not only in phytobiome research and practical plant-probiotic interactions but also for strawberry production.

\section{MATERIALS AND METHODS}

Bacterial strains, plasmids, and culture conditions.

Strains and plasmids used in this study are listed in Table 2. For the preparation of Streptomyces spore stock, a single colony was inoculated into $5 \mathrm{ml}$ of PDK broth and was shaken at $30^{\circ} \mathrm{C}$ for 5 days. The cells were collected by centrifugation at $5,000 \times$ $g$ for $15 \mathrm{~min}$, were suspended in $1 \mathrm{ml}$ of PDK broth, were spread on MS agar (20 g of mannitol, $20 \mathrm{~g}$ of soya, $20 \mathrm{~g}$ of agar, 1 liter of distilled water) and were incubated at $30^{\circ} \mathrm{C}$ for 5 days (Kieser et al. 2000). Then, $1 \mathrm{ml}$ of PDK broth was sprayed onto the MS agar and the surface of the plate was scraped to detach

Table 2. Bacterial strains and plasmids used in this study

\begin{tabular}{|c|c|c|}
\hline Strains/plasmids & Description $^{a}$ & Reference \\
\hline \multicolumn{3}{|l|}{ Escherichia coli } \\
\hline DH5 $\alpha$ & $\begin{array}{l}\text { F-, Ф80dlacZAM15, (lacZYA-argF)U169, deoR, recA1, } \\
\text { endA1, hsdR17 (rk-,mk+), phoA, supE44, } \lambda-\text {, thi-1, gyrA96, relA1 }\end{array}$ & Bierman et al. 1992 \\
\hline ET12567/pUZ8002 & $\begin{array}{l}\text { dam-13::Tn9 dcm-6 hsdM; carries RK2 derivative with defective oriT for } \\
\text { plasmid mobilization, } \operatorname{Kan}^{\mathrm{r}}\end{array}$ & Bierman et al. 1992 \\
\hline Streptomyces griseus S4-7 & & Cha et al. 2016 \\
\hline S4-7, lanA & S4-7DlanA::apr & This work \\
\hline S4-7, lanB & S4-7AlanB::apr & This work \\
\hline S4-7, lanC & S4-7 $\Delta$ lanC::apr & This work \\
\hline S4-7, lanL-1 & $\mathrm{S} 4-7 \Delta \operatorname{lan} L-1: \mathrm{apr}$ & This work \\
\hline S4-7, lanL-2 & S4-7AlanL-2::apr & This work \\
\hline S4-7, lanM & S4-7DlanM::apr & This work \\
\hline \multicolumn{3}{|l|}{ Plasmid/cosmid } \\
\hline $\mathrm{pKC} 1132$ & $\begin{array}{l}\text { Suicide vectors for Streptomyces containing oriT RK2 for } \\
\text { conjugation from E. coli to Streptomyces spp. }\end{array}$ & Kieser et al. 2000 \\
\hline $\mathrm{pKC}$, lan $\mathrm{A}$ & pKC 1132 containing lanA region & This work \\
\hline $\mathrm{pKC}, \operatorname{lan} B$ & pKC 1132 containing lanB region & This work \\
\hline $\mathrm{pKC}, \operatorname{lan} C$ & pKC 1132 containing lan $C$ region & This work \\
\hline $\mathrm{pKC}$, lanL-1 & pKC 1132 containing lanL-1 region & This work \\
\hline $\mathrm{pKC}$, lanL-2 & pKC 1132 containing lanL-2 region & This work \\
\hline $\mathrm{pKC}$, lanM & pKC 1132 containing lanM region & This work \\
\hline
\end{tabular}

${ }^{\mathrm{a}} \mathrm{Kan}^{\mathrm{r}}=$ kanamycin-resistant. 
the spores from the mycelia. The spore suspension was filtered through sterile cotton in a syringe $(15 \mathrm{ml})$, and the filtrate $(800 \mu \mathrm{l})$ and $800 \mu \mathrm{l}$ of $20 \%$ glycerol were mixed together in an Eppendorf tube and were stored at $-20^{\circ} \mathrm{C}$.

\section{S4-7 genome sequencing (PacBio) and annotation.}

Bacterial cells were grown in TSB broth containing $20 \%$ sucrose. Genomic DNA $(1 \mu \mathrm{g})$ isolated by the cetyltrimethylammonium bromide (CTAB) method was used to amplify the lantipeptide genes. Sequencing was carried out by Pacific Biosciences. Sequencing employed the RSII system, a process enabling SMRT technology assembly methods, consisted of nonhybrid approaches, including the Hierarchical Genome Assembly Process (HGAP) 2 for both preassembly and de novo assembly (PacBio).

The BRIG program served to help create the genome circular map (Alikhan et al. 2011). Annotation was carried out using RAST version 2.0 and the classic RAST pipeline, release70 FIGfam (Aziz et al. 2008). For antiSMASH version 3.0.5, sequences were analyzed with the cluster finder algorithm, minimum cluster size coding sequence of five, minimum cluster finder probability score of 0.6 , and the remaining options set automatically (Medema et al. 2011). The Streptomyces griseus S4-7 sequence is available at NCBI as GenBank assembly accession GCA_000932225.1, WGS Project JYBE01.

\section{Generation of lantipeptide mutants.}

Genomic DNA $(1 \mu \mathrm{g})$ isolated by the CTAB method was used to amplify the six lantipeptide genes. To generate knock-out mutants of the lantipeptide genes, left arm (LA) and right arm (RA) fragments were synthesized with primer sets (Supplementary Table S5), were linked by PCR, and were amplified with LA F and RA R primers, yielding the cloned gene with flanking sequences. PCR was carried out in an MJ Research PTC-200 thermal cycler (Bio-Rad). The resulting linked constructs were cloned into the pGEM T vector (Promega), were transformed into Escherichia coli $\mathrm{DH} 5 \alpha$, and were identified by blue or white selection on Luria Bertani (LB) agar containing ampicillin $(100 \mu \mathrm{g} / \mathrm{ml})$ and X-gal $(40 \mu \mathrm{g} / \mathrm{ml})$. After color selection, the inserted DNA in pGEM-T was cut by restriction enzymes $X b a \mathrm{I}$ and $E c o$ RV (NEB). Next, the insert was ligated into plasmid pKC1132 and was transferred to the Streptomyces conjugation strain E. coli ET12567, with selection on LB agar containing kanamycin $(30 \mu \mathrm{g} / \mathrm{ml})$, chloramphenicol $(25 \mu \mathrm{g} / \mathrm{ml})$, and apramycin $(50 \mu \mathrm{g} / \mathrm{ml})$.

To generate mutants, $E$. coli $\mathrm{ET} 12567$ containing the cloned lantipeptide fragments in pKC1152 was mixed into a S4-7 spore stock and was spread on MS agar. Sixteen hours later, apramycin $(50 \mu \mathrm{g} / \mathrm{ml})$ and nalidixic acid $(25 \mu \mathrm{g} / \mathrm{ml})$ were overlaid onto the MS agar plates. After 7 days, the resulting colonies were streaked sequentially three times, on MS agar containing apramycin $(50 \mu \mathrm{g} / \mathrm{ml})$, to obtain single crossovers (Kieser et al. 2000). To obtain double cross-over mutants, the colonies were transferred onto MS agar without antibiotics (Bierman et al. 1992).

\section{Antagonism tests.}

Ten microliters of a bacterial suspension of strain S4-7 and its mutants at an optical density at $595 \mathrm{~nm}$ of 2.0 was streaked with a wooden stick in two lines $3 \mathrm{~cm}$ long onto a plate of PDK agar. After 3 days, an agar block of a culture of the fungal pathogen was inoculated at the center of the plate, $2 \mathrm{~cm}$ from each of the bacterial streaks. Five days later, antifungal activity was assessed based on the size of the inhibition zone and was denoted as follows: no inhibition, + (very weak); 0 to $1 \mathrm{~mm},++$ (weak); $>1$ to $5 \mathrm{~mm},+++$ (moderate); $>5$ to $10 \mathrm{~mm}$, ++++ (strong); $>10$ to $20 \mathrm{~mm},+++++$ (very strong) (Nguyen et al. 2012).

\section{Total RNA extraction and qRT-PCR.}

Total RNA was extracted three times, at vegetative hyphal formation $(24 \mathrm{~h})$, aerial hyphae formation $(48 \mathrm{~h})$, and after formation of aerial hyphae $(72 \mathrm{~h})$. RNA was isolated by the TRIzol method and was purified with an RNeasy Mini kit (Qiagen), according to manufacturer protocols, with liquid nitrogen grinding (Van Dessel et al. 2004). The extracted RNA was stored at $-80^{\circ} \mathrm{C}$. qRT-PCR was performed relative to expression of a set of housekeeping genes. RNA $(1 \mu \mathrm{g})$ was used to amplify a cDNA library with the ReverTraAce- $\alpha$-cDNA synthesis kit (Toyobo). Each reaction included primers for lanM and the housekeeping genes $h r d \mathrm{~A}, \operatorname{gry} \mathrm{A}$, and $r e c \mathrm{~A}$.

\section{qRT-PCR of rhizosphere DNA from soil samples.}

A total of 30 soil samples, each with three biological replications, was collected during strawberry cultivation from three geographically different regions, including Sugok-myeon, Sancheong-gun, and Hadong-gun. For extraction, soil (0.5 g) was homogenized in $978 \mu \mathrm{l}$ of sodium phosphate buffer and $122 \mu \mathrm{l}$ of MT buffer (MP Biomedicals) with a bead beater for 5 min at maximum speed. The Fast DNA spin kit (QBiogene, MP Biomedicals) served to extract the soil DNA, which was stored at $-80^{\circ} \mathrm{C}$. A specific fragment between the transcription factors Han and Skippy was used to detect $F$. oxysporum f. sp. fragariae with primers FofraF (5'-CAGACTGGGGTGCT TAAAGTT- $\left.3^{\prime}\right)$ and FofraR (5'-AACGCTAGGGTCGTAA CAAA-3') (Hong et al. 2018; Suga et al. 2013). Primers StrepB (5'-GTAAAACGACGGCCAGT-3') and StrepE (5'-AACAGC TATGACCAT-3') were used to detect Streptomyces spp. (Rintala et al. 2001). For qRT-PCR, soil DNA was diluted 10fold with double distilled (dd) $\mathrm{H}_{2} \mathrm{O}$, and $5 \mu \mathrm{l}$ was amplified with $25 \mu \mathrm{l}$ of SYBR green mixture (Toyobo) and $\mathrm{ddH}_{2} \mathrm{O}$ up to $50 \mu \mathrm{l}$. A CFXConnect OpticsModule Real-Time PCR system (BioRad) was used for qRT-PCR.

\section{Evaluation of disease incidence and severity of Fusarium wilt in fields.}

Five plots were randomly designated in each field and each plot had 50 to 55 strawberry plants. The plants with Fusarium wilt symptoms were evaluated. The disease severity was evaluated on a disease index scale from 0 to 5: $0=$ healthy, $1=$ one to three leaves yellowed and rolled, $2=$ more than three leaves rolled and deformed, $3=$ chlorosis and early plant wilting, $4=$ necrosis and entire plant wilting, and $5=$ dead or nearly so.

\section{Statistics analysis.}

The data were analyzed using SigmaPlot (Windows ver. 11.0; System Software Inc.). analysis of variance was used to examine differences between means. The dot plot graph was visualized by ggplots version 3.0.1 and ggplot 2 version 2.1.0 (R package).

\section{LITERATURE CITED}

Alabouvette, C., Lemanceau, P., and Steinberg, C. 1993. Recent advances in the biological control of Fusarium wilts. Pest Manag. Sci. 37:365-373.

Alikhan, N. F., Petty, N. K., Ben Zakour, N. L., and Beatson, S. A. 2011. BLAST Ring Image Generator (BRIG): Simple prokaryote genome comparisons. BMC Genomics 12:402.

Aziz, R. K., Bartels, D., Best, A. A., DeJongh, M., Disz, T., Edwards, R. A., Formsma, K., Gerdes, S., Glass, E. M., Kubal, M., Meyer, F., Olsen, G. J., Olson, R., Osterman, A. L., Overbeek, R. A., McNeil, L. K., Paarmann, D., Paczian, T., Parrello, B., Pusch, G. D., Reich, C., Stevens, R., Vassieva, O., Vonstein, V., Wilke, A., and Zagnitko, O. 2008. The RAST Server: Rapid annotations using subsystems technology. BMC Genomics 9:75.

Baayen, R. P., O’Donnell, K., Bonants, P. J., Cigelnik, E., Kroon, L. P., Roebroeck, E. J., and Waalwijk, C. 2000. Gene genealogies and AFLP analyses in the Fusarium oxysporum complex identify monophyletic 
and nonmonophyletic formae speciales causing wilt and rot disease. Phytopathology 90:891-900.

Bagley, M. C., Dale, J. W., Merritt, E. A., and Xiong, X. 2005. Thiopeptide antibiotics. Chem. Rev. 105:685-714.

Bakker, M. G., Glover, J. D., Mai, J. G., and Kinkel, L. L. 2010. Plant community effects on the diversity and pathogen suppressive activity of soil streptomycetes. Appl. Soil Ecol. 46:35-42.

Baltz, R. H. 2008. Renaissance in antibacterial discovery from actinomycetes. Curr. Opin. Pharmacol. 8:557-563.

Beckman, C. H. 1987. The Nature of Wilt Diseases of Plants. APS Press, St. Paul, MN, U.S.A

Bierman, M., Logan, R., O’Brien, K., Seno, E. T., Rao, R. N., and Schoner, B. E. 1992. Plasmid cloning vectors for the conjugal transfer of DNA from Escherichia coli to Streptomyces spp. Gene 116:43-49.

Breukink, E., Wiedemann, I., van Kraaij, C., Kuipers, O. P., Sahl, H. G., and de Kruijff, B. 1999. Use of the cell wall precursor lipid II by a poreforming peptide antibiotic. Science 286:2361-2364.

Cha, J. Y., Han, S., Hong, H. J., Cho, H., Kim, D., Kwon, Y., Kwon, S. K., Crüsemann, M., Bok Lee, Y., Kim, J. F., Giaever, G., Nislow, C., Moore, B. S., Thomashow, L. S., Weller, D. M., and Kwak, Y. S. 2016. Microbial and biochemical basis of a Fusarium wilt-suppressive soil. ISME J. 10:119-129.

Cho, G., Kim, J., Park, C. G., Nislow, C., Weller, D. M., and Kwak, Y. S. 2017. Caryolan-1-ol, an antifungal volatile produced by Streptomyces spp. inhibits the endomembrane system of fungi. Open Biol. 7:170075.

De Cal, A., Martinez-Treceno, A., Salto, T., López-Aranda, J., and Melgarejo, P. 2005. Effect of chemical fumigation on soil fungal communities in Spanish strawberry nurseries. Appl. Soil Ecol. 28:47-56.

Dufour, A., Hindré, T., Haras, D., and Le Pennec, J. P. 2007. The biology of lantibiotics from the lacticin 481 group is coming of age. FEMS Microbiol. Rev. 31:134-167.

Engelhardt, K., Degnes, K. F., Kemmler, M., Bredholt, H., Fjaervik, E. Klinkenberg, G., Sletta, H., Ellingsen, T. E., and Zotchev, S. B. 2010. Production of a new thiopeptide antibiotic, TP-1161, by a marine Nocardiopsis species. Appl. Environ. Microbiol. 76:4969-4976.

Foulston, L. C., and Bibb, M. J. 2010. Microbisporicin gene cluster reveals unusual features of lantibiotic biosynthesis in actinomycetes. Proc. Natl. Acad. Sci. U.S.A. 107:13461-13466

Garg, N., Salazar-Ocampo, L. M. A., and van der Donk, W. A. 2013. In vitro activity of the nisin dehydratase NisB. Proc. Natl. Acad. Sci. U.S.A. 110: 7258-7263.

Goto, Y., Li, B., Claesen, J., Shi, Y., Bibb, M. J., and van der Donk, W. A 2010. Discovery of unique lanthionine synthetases reveals new mechanistic and evolutionary insights. PLoS Biol. 8:e1000339.

Hofmann, F. T., Szostak, J. W., and Seebeck, F. P. 2012. In vitro selection of functional lantipeptides. J. Am. Chem. Soc. 134:8038-8041.

Hong, S. W., Kim, D. R., Kim, J. S., Cho, G. J., Jeon, C. W., and Kwak, Y. S. 2018. Development qRT-PCR protocol to predict strawberry Fusarium wilt occurrence. Plant Pathol. J. 34:163-170

Kapoor, I. 1988. Fungi involved in tomato wilt syndrome in Delhi, Maharashtra and Tamil Nadu. Indian Phytopathol. 41:208-213.

Kieser, T., Bibb, M. J., Buttner, M. J., Chater, K. F., and Hopwood, D. A. 2000 Practical Streptomyces genetics. John Innes Foundation, Norwich, England.

Knerr, P. J., and van der Donk, W. A. 2012. Chemical synthesis and biological activity of analogues of the lantibiotic epilancin 15X. J. Am. Chem. Soc. 134:7648-7651.

Kwak, Y. S., and Weller, D. M. 2013. Take-all of wheat and natural disease suppression: A review. Plant Pathol. J. 29:125-135.

Li, B., and van der Donk, W. A. 2007. Identification of essential catalytic residues of the cyclase NisC involved in the biosynthesis of nisin. J. Biol. Chem. 282:21169-21175

Liu, X., Wang, J., Gou, P., Mao, C., Zhu, Z. R., and Li, H. 2007. In vitro inhibition of postharvest pathogens of fruit and control of gray mold of strawberry and green mold of citrus by aureobasidin A. Int. J. Food Microbiol. 119:223-229.

Lubelski, J., Rink, R., Khusainov, R., Moll, G. N., and Kuipers, O. P. 2008 Biosynthesis, immunity, regulation, mode of action and engineering of the model lantibiotic nisin. Cell. Mol. Life Sci. 65:455-476.
Mavrodi, O. V., Mavrodi, D. V., Thomashow, L. S., and Weller, D. M. 2007. Quantification of 2,4-diacetylphloroglucinol-producing Pseudomonas fluorescens strains in the plant rhizosphere by real-time PCR. Appl. Environ. Microbiol. 73:5531-5538.

Mazurier, S., Corberand, T., Lemanceau, P., and Raaijmakers, J. M. 2009. Phenzaine antibiotics produced by fluorescent pseudomonads contribute to natural soil suppressiveness to Fusarium wilt. ISME J. 8:977-991.

McAuliffe, O., Ross, R. P., and Hill, C. 2001. Lantibiotics: Structure, biosynthesis and mode of action. FEMS Microbiol. Rev. 25:285-308.

Medema, M. H., Blin, K., Cimermancic, P., de Jager, V., Zakrzewski, P., Fischbach, M. A., Weber, T., Takano, E., and Breitling, R. 2011. antiSMASH: Rapid identification, annotation and analysis of secondary metabolite biosynthesis gene clusters in bacterial and fungal genome sequences. Nucleic Acids Res. 39 (suppl_2):W339-W346.

Nguyen, X., Naing, K., Lee, Y., Tindwa, H., Lee, G., Jeong, B., Ro, H., Kim, S., Jung, W., and Kim, K. 2012. Biocontrol potential of Streptomyces griseus $\mathrm{H} 7602$ against root rot disease (Phytophthora capsici) in pepper. Plant Pathol. J. 28:282-289.

Raaijmakers, J. M., and Weller, D. M. 1998. Natural plant protection by 2, 4-diacetylphloroglucinol-producing Pseudomonas spp. in take-all decline soils. Mol. Plant-Microbe Interact. 11:144-152.

Rintala, H., Nevalainen, A., Rönkä, E., and Suutari, M. 2001. PCR primers targeting the 16S rRNA gene for the specific detection of streptomycetes. Mol. Cell. Probes 15:337-347.

Scher, F. M., and Baker, R. 1980. Mechanism of biological control in a Fusarium-suppressive soil. Phytopathology 70:412-417.

Scher, F. M., and Baker, R. 1982. Effect of Pseudomonas putida and a synthetic iron chelator on induction of soil suppressiveness to Fusarium wilt pathogens. Phytopathology 72:1567-1573.

Sneh, B., Dupler, M., Elad, Y., and Baker, R. 1984. Chlamydospore germination of Fusarium oxysporum f. sp. cucumerinum as affected by fluorescent and lytic bacteria from Fusarium-suppressive soil. Phytopathology 74:1115-1124.

Suga, H., Hirayama, Y., Morishima, M., Suzuki, T., Kageyama, K., and Hyakumachi, M. 2013. Development of PCR primers to identify Fusarium oxysporum f. sp. fragariae. Plant Dis. 97:619-625.

Ueda, K., Oinuma, K., Ikeda, G., Hosono, K., Ohnishi, Y., Horinouchi, S., and Beppu, T. 2002. AmfS, an extracellular peptidic morphogen in Streptomyces griseus. J. Bacteriol. 184:1488-1492.

Van Dessel, W., Van Mellaert, L., Geukens, N., Lammertyn, E., and Anné, J. 2004. Isolation of high quality RNA from Streptomyces. J. Microbiol. Methods 58:135-137.

Weller, D. M., Raaijmakers, J. M., Gardener, B. B. M., and Thomashow, L. S. 2002. Microbial populations responsible for specific soil suppressiveness to plant pathogens. Annu. Rev. Phytopathol. 40:309-348.

Yu, Y., Zhang, Q., and van der Donk, W. A. 2013. Insights into the evolution of lanthipeptide biosynthesis. Protein Sci. 22:1478-1489.

Zhang, Q., Doroghazi, J. R., Zhao, X., Walker, M. C., and van der Donk, W. A. 2015. Expanded natural product diversity revealed by analysis of lantipeptide-like gene clusters in actinobacteria. Appl. Environ. Microbiol. 81:4339-4350.

Zhang, Q., Yu, Y., Vélasquez, J. E., and van der Donk, W. A. 2012. Evolution of lanthipeptide synthetases. Proc. Natl. Acad. Sci. U.S.A. 109:18361-18366.

Živković, S., Stojanović, S., Ivanović, Ž., Gavrilović, V., Popović, T., and Balaž, J. 2010. Screening of antagonistic activity of microorganisms against Colletotrichum acutatum and Colletotrichum gloeosporioides. Arch. Biol. Sci. 62:611-623.

\section{AUTHOR-RECOMMENDED INTERNET RESOURCES}

antiSMASH program: https://antismash.secondarymetabolites.org

BRIG (BLAST Ring Image Generator) software:

http://courceforge.net/progects/brig

NCBI website: https://www.ncbi.nlm.nih.gov

RAST annotation service: http://rast.nmpdr.org 